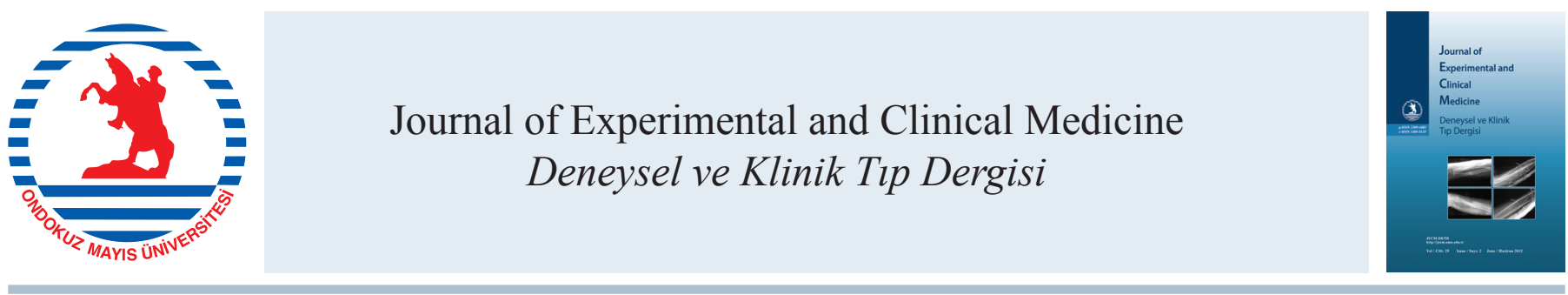

Olgu Sunumu / Case Report

doi: $10.5835 /$ jecm.omu.29.02.016

\title{
Kalsifiye kronik subdural hematom
}

\section{Calcified chronic subdural hematoma}

Mustafa Aras*, Murat Altaş, Atilla Yılmaz, Yurdal Serarslan, Boran Urfalı, Nebi Yılmaz

Mustafa Kemal Üniversitesi, Tayfur Ata Sökmen Tıp Fakültesi, Beyin ve Sinir Cerrahisi Anabilim Dalı, Hatay, Türkiye

\begin{tabular}{|c|c|}
\hline MAKALE BİLGÍLERİ & jZET \\
\hline $\begin{array}{ll}\text { Makale geçmişi } \\
\text { Geliş tarihi } & : 06 \text { / } 07 \text { / } 2011 \\
\text { Kabul tarihi } & : 14 \text { / } 07 \text { / } 2011\end{array}$ & $\begin{array}{l}\text { Kalsifiye kronik subdural hematom nadir karşılaşılan bir hastalıktır. Bu durum, geçirilmiş } \\
\text { travmalara veya yetersiz cerrahi girişimlere ikincil olarak gelişebilir. Etiyolojisi } \\
\text { halen net olarak anlaşılamadığından tedavi şekli konusunda ihtilaflar mevcuttur. }\end{array}$ \\
\hline $\begin{array}{l}\text { * Yazışma Adresi: } \\
\text { Mustafa Aras } \\
\text { Mustafa Kemal Üniversitesi } \\
\text { Tıp Fakültesi, } \\
\text { Beyin ve Sinir Cerrahisi Ana Bilim Dalı, } \\
\text { 31700, Hatay } \\
\text { e-posta: maras.70@hotmail.com }\end{array}$ & $\begin{array}{l}\text { Bu makalede, kalsitıye kronık subdural hematomlu, } 2 / \text { yaşında erkek hasta sunuldu. } \\
\text { Hastanın } 5 \text { y1l önce trafik kazası sonrası başka bir merkezde ameliyat geçirme öyküsü } \\
\text { vardı. Nöbet geçirme, baş ağrısı ve baş dönmesi şikâyeti ile başvurdu. Nörolojik } \\
\text { muayenede patoloji saptanmadı. Nörogörüntülemede, sağ frontotemporoparietal bölgede } \\
\text { kalsifiye kronik subdural hematom tespit edildi. Antiepileptik ve analjezik ilaç uygulamas } \\
\text { ile izleme alındı.Kalsifiye kronik subdural hematomlu olgularda, cerrahi tedavi kararı } \\
\text { dikkatli ve titiz bir değerlendirme sonrasında verilmeli ve hastaya fayda sağlamayacak } \\
\text { cerrahi işlemlerden kaçınılmalıdır. Klinik izlem göz önünde bulundurulmalıdır. } \\
\text { J. Exp. Clin. Med., 2012;29:159-161 }\end{array}$ \\
\hline
\end{tabular}

\section{Anahtar Kelimeler:}

Kronik subdural hematom

Kalsifikasyon

Zirhlı beyin

Travma

Epilepsi

Vasküler tromboz

Key words:

Chronic subdural hematoma

Calcification

Armored brain

Trauma

Epilepsy

Vascular thrombosis

\begin{abstract}
Calcified subdural hematoma is a rarely seen event. It may develop secondary to previous trauma or inappropriate surgical procedures. Due to the not well understood etiology, there are variations in the treatment choices. We present a 27 -year old male patient with calcified chronic subdural hematoma. He was operated on following an motorcycle accident in another hospital 5 years ago. He was admitted to our hospital complaining about seizure, headache and dizziness. Neuroradiological examination revealed a calcified chronic subdural hematoma was detected on the right hemisphere. The patient was hospitalized and put on anti-epileptic and analgesic drugs. Any surgical treatment was not applied. In cases with calcified chronic subdural hematoma, the decision of surgical operation should be decided after a carefully and meticulously investigation. It should be avoided any profitless and likely harmful surgical procedures. The clinical observation may be appropriate in the determination of treatment approaches. J. Exp. Clin. Med., 2012; 29:159-161
\end{abstract}

\section{Giriş}

Kalsifiye kronik subdural hematom nadir görülen bir hastalıktır (Rahman ve ark., 2012; Sharma ve ark., 1999). Genellikle çocuklar ve genç erişkinlerde görülür (İplikçioğlu ve ark., 1991; Erşahin ve Mutluer, 2000). Oluş mekanizmaları halen tam olarak ortaya konamamış ve bu yüzden de tedavi yaklaşımları konusunda net bir fikir birliği sağlanamamıştır (İplikçioğlu ve ark., 1991; Delgado-López ve ark., 2009; Oda ve ark., 2010). Kronik subdural hematomların \% 0,3-2,7'sinde kalsifikasyon veya ossifikasyon bulunabilir (İplikçioğlu ve ark., 1991; Kavcic ve ark., 2006). Kortikal yüzeyin geniş bir bölümünü kapsayan büyük kalsifiye kronik subdural hematom olguları "Zirhlı Beyin" olarak adlandırılır (Oda ve ark., 2010). Kalsifiye kronik subdural hematomlu olguların bir kısmı asemptomatik seyrederken, bir kısmı da epileptik nöbetler ve baş ağrısı gibi şikayetlerle müracaat edebilir (Sgaramella ve ark., 2002; Dammers ve ark., 2007). $\mathrm{Bu}$ olgu sunumunda havale geçirme, baş ağrısı ve aralıklı baş dönmesi şikâyeti olan ve nörolojik muayenesi normal olup opere edilmeyerek klinik izleme alınan bir olgu sunulmuştur.

\section{Olgu}

27 yaşında erkek hasta kliniğimize nöbet geçirme ve aralıklı baş dönmesi şikâyeti ile başvurdu. Öyküsünde 5 yıl önce 
motorsiklet kazası geçirdiği ve başka bir merkezde subdural hematom tanısıyla ameliyat edildiği saptandı. Nörolojik muayenesinde herhangi bir patoloji saptanmadi. Kraniyografi (Şek. 1), kraniyal bilgiyasarlı görüntüleme (BT) (Şek. 2 ve Şek. 3) ve manyetik rezonans görüntülemede (MRG) (Şek. 4), sağ fronto temporoparietal bölgede kalsifiye kronik subdural hematom tespit edildi. Antiepileptik ve analjezik ilaç uygulamasını içeren tıbbi tedavinin ardından şikâyetleri düzelen hasta tavsiyelerle taburcu edilerek klinik izleme alındı. Son bir yıllık takiplerinde herhangi bir şikayet ve tıbbi problem olmadi.

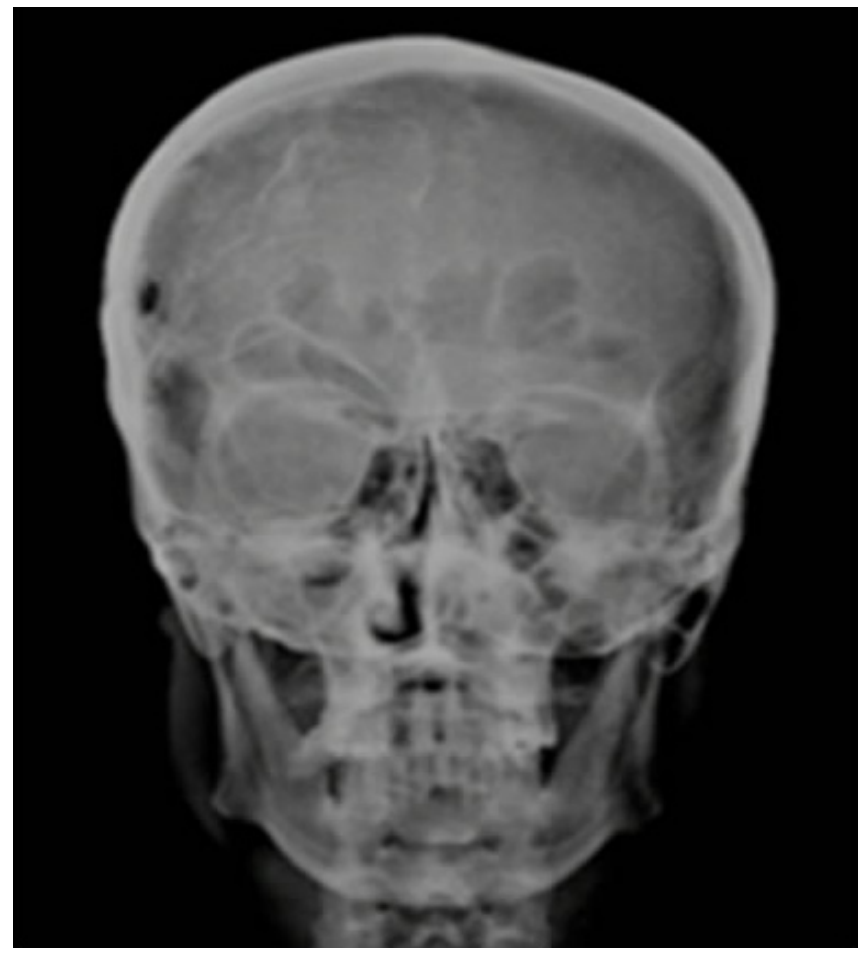

Şek. 1. Direk kraniyografide kalsifikasyon izlenmekte

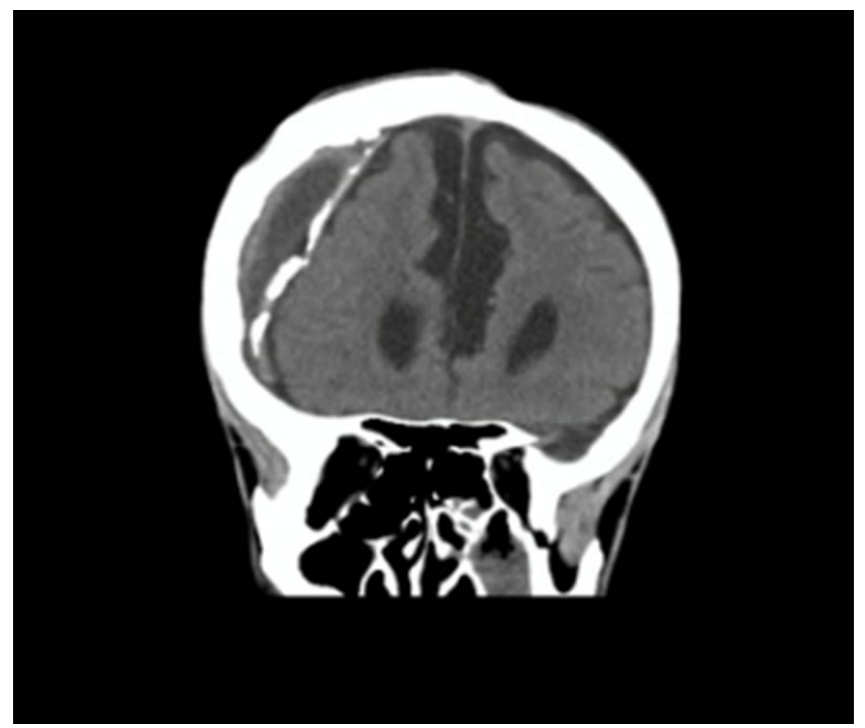

Şek. 2. Koronal opaksız BT kesitlerinde frontoparietal alanda kalsifiye kronik subdural hematom izlenmekte

\section{Tartışma}

Kronik subdural hematomlarda kalsifikasyon gelişme mekanizması ve neden tümünde kalsifikasyon olmadığı halen

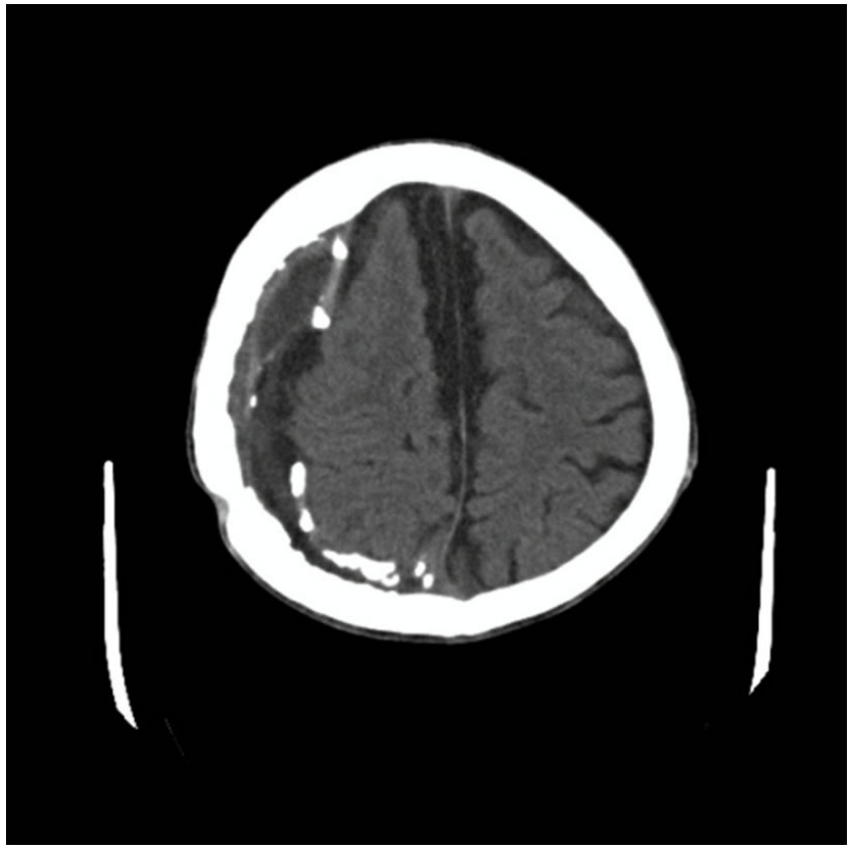

Şek. 3. Aksiyel opaksız BT kesitlerinde frontoparietal alanda kalsifiye kronik subdural hematom izlenmekte

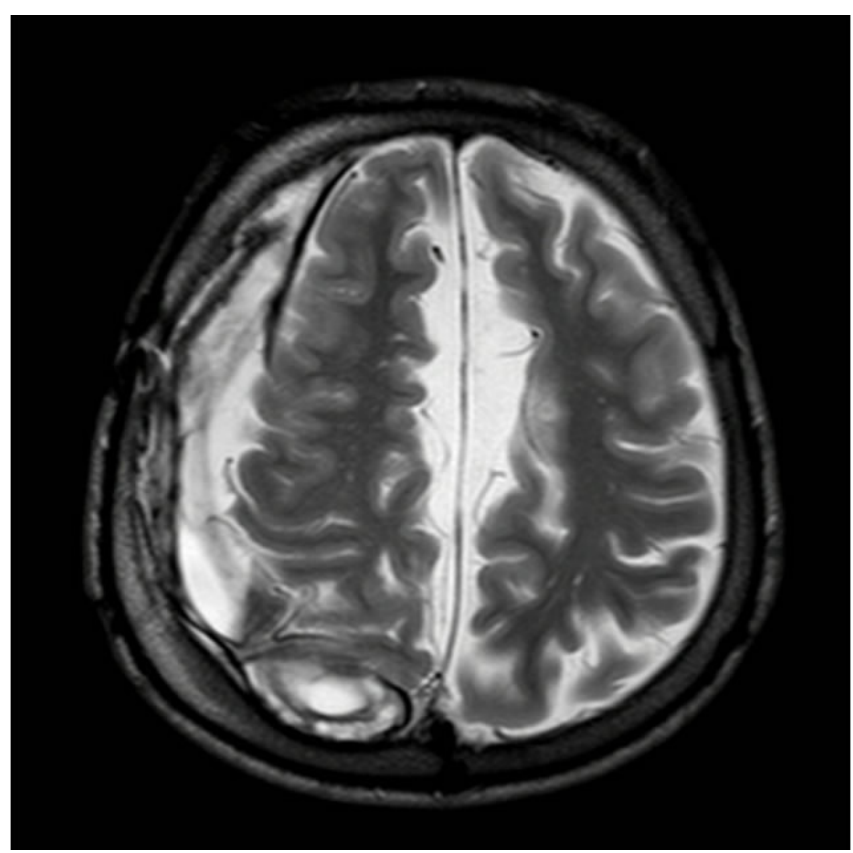

Şek. 4. MRG'de T2 ağırlıklı kesitlerde hipo-hiperintens, heterojen karakterde frontoparietal subdural kolleksiyon izlenmekte

tam aydınlatılamamıştır. Bazı yazarlara göre subdural mesafedeki azalmış sirkülasyon, absorpsiyon ve vasküler trombozlar kalsifikasyondan sorumlu olabileceği gibi bazılarına göre de lokal faktörler ve metabolik yatkınlık kalsifikasyon sebebidir (Sgaramella ve ark., 2002). Kalsifikasyon gelişimi ile kanama arasında geçen süre genellikle 6 aydan daha uzundur (Ludwig ve ark., 1983; İplikçioğlu ve ark., 1991; Sgaramella ve ark., 2002; Kavcic ve ark., 2006; Dammers ve ark., 2007). Birçok olguda kalsifiye kronik subdural hematomun şant ameliyatlarından sonra ve menenjite sekonder geliştiği bildirilmiştir. Travma sonrası ortaya çıkan kronik subdural hematomlarda kalsifikasyon gelişme riski diğer nedenlerle ortaya çıkanlara göre daha yüksektir (Ludwig ve ark., 1983; Sharma ve ark., 1999; He ve Zhang, 2005). Bazı olgularda 
nörolojik arazlar görülmesine karşılık intrakranyal basınç artışına bağlı semptomlar yoktur. Bu olgularda başlangıçtaki travma veya inflamatuar değişikliklere sekonder olarak gelişen atrofi ya da beyin hasarı semptomların gelişmesinden sorumlu olabilir (Ludwig ve ark., 1983). Kraniyografilerde kalsifikasyon görülebileceği gibi BT ve MRG ile detaylı bilgiler elde edilebilir.

Kalsifiye kronik subdural hematomlu olgularda cerrahi tedavi kararı verilmeden önce hastalar çok dikkatli değerlendirilmeli ve gerekli olmayan bir cerrahi girişimin yarar sağlamayacağı bilinmelidir. Gereksiz yere yapılan bir cerrahi müdahalenin hastanın klinik olarak daha da gerilemesine sebep olabileceği akılda tutulmalıdır. Bizim olgumuza nörolojik muayenesinin normal olması, şikayetlerinin semptomatik tedavi ile düzelmesi nedeniyle cerrahi müdahale planlamadık ve klinik izleme kararı aldık. Hastalığın başlangıcındaki travma veya inflamatuar sebeplere sekonder olarak ortaya çıkan atrofi veya beyin hasarının semptomların gelişiminden sorumlu olabileceği akılda tutulmalı ve tedavi planı buna göre kurgulanmalidır.

\section{KAYNAKLAR}

Dammers, R., ter Laak-Poort, M.P., Maas, A.I., 2007. Neurological picture. Armoured brain: case report of a symptomatic calcified chronic subdural haematoma. J. Neurol. Neurosurg. Psychiatry. 78, 542-543.

Delgado-López, P.D., Martín-Velasco, V., Castilla-Díez, J.M., Rodríguez-Salazar, A., Galacho-Harriero, A.M., Fernández-Arconada, O., 2009. Dexamethasone treatment in chronic subdural haematoma. Neurocirugia (Astur). 20, 346-359.

Erşahin, Y., Mutluer, S., 2000. Calcified Subdural Hematoma. Pediatr. Neurosurg. 32,165-166.

He, X.S., Zhang, X., 2005. Giant calcified chronic subdural hematoma: A long term complication of shunt hydrocephalus. J. Neurol. Neurosurg. Psychiatry. 76, 367.

İplikçioğlu, A.C., Akkaş, Ö., Sungur, R., 1991. Ossified chronic subdural hematoma: Case report. J. Trauma. 31, $272-275$.

Kavcic, A., Meglic, B., Meglic, N.P., Vodusek, D.B., Mesec A., 2006. Asymptomatic huge calcified subdural hematoma in a patient on oral anticoagulant therapy. Neurology. 66, 758.

Ludwig, B., Nix, W., Lanksch, W., 1983. Computerized tomography of the armored brain. Neuroradiology. 25, 39-43.

Oda, S., Shimoda, M., Hoshikawa K., Shiramizu, H., Matsumae, M., 2010. Organized chronic subdural haematoma with a thick calcified inner membrane successfully treated by surgery: a case report. Tokai J. Exp. Clin. Med. 35, 85-88.

Rahman, A., Haque, M., Bhandari, PB., 2012. Calcified chronic subdural haematoma. BMJ Case Rep., doi: 10.1136/bcr.01.2012.5499.

Sgaramella, E., Sotgiu, S., Miragliotta, G., Fotios Kalfas Crotti, F.M., 2002."Matrioska head". Case report of calcified chronic subdural hematoma. J. Neurosurg. Sci. 46, 28-31.

Sharma, R.R., Mahapatra, A., Pawar, S.J., Sousa, J., Athale, S.D., 1999. Symptomatic calcified subdural hematomas. Pediatr. Neurosurg. 31, $150-154$. 